\title{
Benchmark-Based Preferences Make Investors Loss Averse in Bull Markets and Gain Seeking in Bear Markets
}

\author{
Robert Bordley ${ }^{1} \&$ Luisa Tibiletti ${ }^{2}$ \\ ${ }^{1}$ Department of Industrial Engineering and Operations Management, University of Michigan, USA email: \\ rbordley@umich.edu \\ ${ }^{2}$ Department of Management, University of Torino, Italy, email: luisa.tibiletti@unito.it \\ Correspondence: Luisa Tibiletti, School of Management, Department of Management, University of Torino, Italy. \\ E-mail: luisa.tibiletti@unito.it
}

Received: October 31, 2017

Accepted: November 18, 2017

Online Published: December 20, 2017

doi:10.5539/ijbm.v13n1p46

URL: https://doi.org/10.5539/ijbm.v13n1p46

\begin{abstract}
Recent empirical studies have shown that investors are far more likely to be loss averse during bull markets than during bear ones. The aim of this short note is to give solid foundations to this empirical evidence. Using the benchmark-based preference method we establish a direct connection between the individual perception of the market trend and the individual risk preferences. Then we develop a novel definition of loss aversion and gain seeking which intuitively captures the human attitudes described by the quotes "losses loom larger than gains" and "gains loom larger than losses", respectively. Our findings have also practical applications. In fact they may offer a solid explanation to the disposition effect. According to this cognitive bias in bull markets investors are driven by loss aversion and tend to sell winners too early; whereas in bear markets investors are driven by gain seeking and tend to hold losers too long.
\end{abstract}

Keywords: Bull and bear markets, loss-gain asymmetry, benchmarking, disposition effect cognitive bias

\section{Introduction}

In recent years behavioral finance and empirical research have demonstrated the influence of market trend perception on private investors' risk preferences. By setting up an asset allocation optimization problem performed in the US and UK financial markets, Hwang and Satchell (2010) argue that investors endowed with a Kahneman-power type utility function, are far more loss averse during bull markets than during bear ones (see also Hofschire, Embo-Mattingly, Gold \& Blackwell, 2013).

The aim of this short note is to provide solid foundations to this human attitude and show that investors' risk preferences are normatively driven by the mismatch between the subjective performance benchmark and market expectations.

First, we formalize the concept of perception of market trends on the basis of investor and market sentiment's mismatched views about the reference-point. Then we use a benchmarking procedure to extrapolate investors' risk preferences according to the benchmark (see Fabozzi, 2009; and Jakóbczak, 2015 for a review). Inspired by the seminal definitions of loss aversion proposed by Markowitz (1952), and subsequently expanded by Kahnemann and Tversky (1979) and Tversky and Kahnemann (1992) we formalize the human pattern described by the Kahnemann and Tversky (1979) dictum "losses loom larger than gains", where losses and gains are referred to investors' personal reference points.

Finally, under mild technical assumptions, which are fulfilled by the most common utility functions, we demonstrate how loss aversion and gain appetite are normatively influenced by personal expectations of market trends.

Our findings also have immediate practical applications. For example they offer a normative explanation to the disposition effect, that is the popular biased behavior that, using Shefrin and Statman (1985)'s words, drives investors to "sell winners too early" in bull markets and to "ride losers too long" in bear markets.

The remainder of the paper is organized as follows. In Section 2, we introduce the definition of perceived market trends. Then we show how to extrapolate investors' risk preferences from the performance benchmark. In 
Section 3, the definitions of loss aversion and gain appetite are given and our main result presented. In Section 4 we give a normative explanation of the disposition effect bias. Section 5 concludes the article. The proof is presented in the Appendix.

\section{How the Reference-Point Influences Investor's Perception of Market Trends}

How investors perceive a bullish or bearish market trend is still an open question in the financial literature (for a review see Duxbury, 2015; and Muradoglu and Harvey, 2012). Traders usually form their opinions on the evaluation of short-term, mid-term and long-term financial index variations. A market switching trend in the US and UK stock markets is usually detected by a variation in the S\&P 500 Index and the FTSE All-share Index, respectively (see Hofschire et al 2013, footnote 1).

Evidence indicates that in real life form ordinary investors their own opinions on a combination of technical analysis and human perception. The evaluations are inherently comparative and benchmark dependent; that is, individuals are inclined to view outcomes not in absolute terms, but relative to a reference-points. Since the benchmark $T$ of an asset performance is usually linked to the performance of uncertain market indices, as the S\&P 500 Index, MSCI World or S\&P Global 100 indices among others, the benchmark $T$ is an uncertain variable, as well.

A familiar way to describe an uncertain variable $T$ is to assess its shape parameters as the mode (the most likely outcome value) and the median (the value that separates the outcome sample into two equally probable sets). In the following section we argue that investors' views about the market trend can be drawn from these two parameters' mismatching.

\subsection{The Investor Reference-Point: The Mode M of the Performance Benchmark}

Heath et al. (1999) and Hoffmann and Kalogeras (2013) argue that individuals dealing with uncertain variables $T$, tend to pick as a reference-point the most likely value, i.e. the mode. From now on, we assume that the uncertain benchmark $T$ is an absolutely continuous and unimodal variable (Note 1). It follows that its cumulative distribution function (c.d.f.) $F$ is convex for outcomes below the mode (Note 2) $M$ and concave for those above. If the mode $M$ coincides with the minimum value of the outcome set, $F$ is concave; if it lies at the maximum value, $F$ is convex (for a characterization of distributions with convex c.d.f. see Gnedin and Pitman, 2008). In most cases, $F$ is S-shaped with the concavity switching point at the mode $M$. These simple comments will turn out to be key elements in the discussion to follow.

\subsection{The Market Sentiment Value: The Median M of the Performance Benchmark}

Market sentiment is defined as the generally prevailing attitude or consensus of the investment community. A growing number of different market sentiment indicators are quoted daily and monthly (see e.g. Forex sentiment indicators; Thomson Reuters MarketPsych Indices (TRMI) among others) and they reflect fundamental and technical factors, including price history, economic reports, seasonal factors, and national and world events.

It is reasonable to assume that market sentiment represents the central value $m$ expressed by the investment community over the uncertain variable $T$. Formally, $m$ is the median of $T$, such as $P(T<m)<0.5$ and $P(T \geq m) \geq 0.5$. Thus defined the median $m$ exists and is unique for any absolutely continuous unimodal variable, as in our case.

Now we are ready to introduce an intuitive definition of individual perception of market trends based on the mismatch between the individual reference-point (i.e. the mode $M$ ) and the market sentiment value (i.e. the median $m$ ).

Definition 1. Let $T$ be an uncertain performance benchmark with mode $M$ and median $m$. Let $M$ be the investor reference-point and $m$ the market sentiment value, then

a) if $M<m$ then the investor perceives a bull market trend;

b) if $M>m$ then the investor perceives a bear market trend;

c) if $M=m$ then the investor perceives a static market trend.

The intuition behind the above definitions is simple. If the investor reference-point $M$, is lower than market sentiment value $m$ then the investor expects that their investment return will outperform its reference-point $M$. Then the investor is prone to forecast a bullish trend; conversely, if reference-point $M$ is greater than the market sentiment value $m$, the investor is prone to expect a bearish trend. Typically the investor chooses the reference-point $M$ equal to the purchase price (see Odean, 1998). 


\subsection{Benchmark-based Asymmetric Preferences}

A long-standing question in behavioral finance is how to assess risk preferences to elicit investors' cardinal utility. Usually elicitation is achieved by submitting computer-run questionnaires concerning choices among alternative lotteries. However, due to difficulty in handling abstract mathematical reasoning respondents may fall into inconsistent answers (for an overview of the prevailing methodologies for eliciting risk preferences ranked according to their complexity see Charness et al., 2013). To overcome these drawbacks we suggest using the benchmarking procedure (see Fabozzi 2009, p. 78 and Jakóbczak 2015 for a review). Following Heath et al. (1999, p. 93)'s claim 'goals inherit the properties of (utility) function', we elicit investors' utility functions through information about investors' benchmarks.

Without loss of generality, we assume that the utility function $u$ is bounded, increasing (but not constant) and continuous, so that $\inf u(x)=0$ and $\sup u(x)=1$. As pointed out by Borch (1968, p. 3) and Berhold (1973, p. $825)$ the normalized $u$ possesses all properties of a probability distribution. Thus, as argued by Bordley and LiCalzi $(2000$, p. 55) the utility function $u$ can be interpreted as the c.d.f. $F$ of the uncertain performance benchmark $T$ to reach (Note 3 ), so

$$
u(x)=P(T \geq x)=F(x)
$$

To put it differently, the equation (1) states that the utility $u(x)$ can be read as the probability that the outcome $x$ exceeds the uncertain benchmark $T$. For example, $u(100 €)$ can be reworded as the probability that the outcome $100 €$ will exceed the benchmark return $T$, rather than as the cardinal utility of $100 €$, and vice versa.

\section{Main Result: Loss Aversion during Bull Markets and Gain Seeking During Bear Markets}

According to the original ideas of Markowitz (1952) subsequently developed by Kahneman and Tversky (1979) and Tversky and Kahneman (1992), we assume that individuals dislike symmetric bets. More precisely, we assume that people: (i) value outcomes as gains or losses relative to a reference-point; (ii) make decisions in terms of gains or losses rather than final wealth; and (iii) weight gains and losses on an S-shaped Kahneman and Tversky utility function with asymmetrical tails. The asymmetric coding mentioned in (iii) can be described by the following statements:

a) "Losses loom larger than gains" (Kahneman and Tversky 1979, p. 279) capturing the idea of loss aversion that investors care more about downside with respect to a reference-point than upside potential outcomes; and

b) "Gains loom larger than losses" (see Sacchi and Stanca 2014; Mellers and Ritov 2010) that identifies investors' inclination towards gain appetite.

Since Kahneman and Tversky (1979) work on behavioral economics numerous definitions of loss aversion have been proposed in the literature (for an ample review see Abdellaoui et al., 2007). In the following definition we use definitions of loss aversion and gain appetite expressing asymmetric preferences with respect to the reference-point, see Bordley, LiCalzi \&Tibiletti (2017) and Bordley, Tibiletti \& Uberti (2016).

Definition 2. Let $u$ be an absolutely continuous cardinal utility function defined on the outcome set $I$ and $x_{0}$ the agent reference-point, with $x_{0} \in I$. Then

a) $u$ exhibits loss aversion with respect to $x_{0}$ if

$$
u\left(x_{0}+x\right)-u\left(x_{0}\right) \leq u\left(x_{0}\right)-u\left(x_{0}-x\right) \text { for all } x \geq 0 \text { such that } x_{0}-x \in I \text { and } x_{0}+x \in I
$$

and

b) $u$ exhibits gain appetite with respect to $x_{0}$ if

$$
u\left(x_{0}+x\right)-u\left(x_{0}\right) \geq u\left(x_{0}\right)-u\left(x_{0}-x\right) \text { for all } x \geq 0 \text { such that } x_{0}-x \in I \text { and } x_{0}+x \in I
$$

In other words, a loss averse agent perceives the increment in utility from making a gain $x \geq 0$ measured from the reference-point $x_{0}$, lower or equal to the increment in disutility from bearing a loss $-x \leq 0$ of equal amount. An agent characterized by gain appetite, displays opposite risk preferences. Clearly, if $x_{0}=0$ and $u(0)=0$, Definition (2.a) reduces to the definition of loss aversion introduced by Kahneman and Tversky (1979, p. 279), $u(x) \leq-u(-x)$ for all $x \geq 0$.

To link personal opinions about the market trend with risk preferences, a technical assumption on $T$ is needed. Let $T$ belong to the class of asymmetric absolutely continuous unimodal distributions fulfilling the van Zwet (1979) asymmetry conditions (Note 4) $u(m+x)+u(m-x) \leq 1$ and $u(m+x)+u(m-x) \geq 1$ for all $x \geq 0$, where $m-x \in I$ and $m+x \in I$ (see also Abadir 2005; Abdous and Theodorescu 1998). Most of the unimodal absolutely continuous asymmetric distributions satisfy these conditions, as for example any Pearson distribution of Type I to XII (see LiCalzi \& Sorato, 2006). 
Our main result follows.

Proposition 1. Let $T$ be an asymmetrical absolutely continuous unimodal performance benchmark with c.d.f. $u$ defined on the outcome set $I$, with mode $M$ and median $m$, where $M \neq m$. Let $T$ satisfy the van Zwet (1979) asymmetry conditions. Assume the investor endowed with the normalized continuous utility function $u$. Then,

a) if the investor perceives a bull market trend (i.e. $M<m$ ), then $u$ exhibits loss aversion with respect to the reference-point $x_{0}=M$;

b) if the investor perceives a bear market trend (i.e. $M>m$ ), then $u$ exhibits gain appetite with respect to the reference-point $x_{0}=M$.

Proposition 1 provides normative grounds to the human inclination towards loss aversion in bull markets and gain appetite in bear markets (see the proof in the Appendix). Almost all utility functions used in Expected Utility Theory and Prospect Theory satisfy the van Zwet (1979) asymmetry conditions, and then apply to Proposition 1 (see Tibiletti, 2017).

\section{An Application: The Disposition Effect Bias}

Proposition 1 traces the normative cause of one of the most common cognitive bias called the disposition effect bias (see Barberis and Xiong, 2009; Kaniel, Saar \& Titmar, 2008, among others). According to that bias investors tend to "selling winners too early and riding losers too long" (see Shefrin and Statman, 1985). This biased attitude has been recently observed in the equity market trading (see Jannatunnesa, 2017).

Since the seminal paper of Pratt (1964), agent's attitude to risk aversion has been associated with a concave utility function, whereas an agent's attitude to risk appetite (Note 5) has been related with a convex utility function. According to the Prospect Theory investors are endowed with an S-shaped Kahneman and Tversky utility function which is convex below the reference-point $M$ and concave above. Clearly, if $M$ is the infimum outcome, the utility function $u$ turns to become concave over all the outcome domain and consequently the investor is risk averse at any market outcome. Opposite preferences to risk come out if $M$ is the supremum market outcome. The utility function $u$ turns to become convex and the investor is risk seeking at any market outcome. For any intermediate case, the S-shaped utility function $u$ represents an investor who is risk seeking in dealing with market outcomes below the reference-point $M$ and risk averse in dealing with market outcomes above $M$.

That result spotlights the relation between the risk preferences and the investor reference-point $M$. The smaller the reference-point $M$, the shorter the outcome interval where $u$ is convex and the longer that interval where $u$ is concave. That indicates that the smaller the reference-point $M$, the less the investor behaves as a risk seeker and the more as a risk averse. Conversely, the higher the reference-point $M$, the longer the outcome interval where $u$ is convex and the shorter the interval where $u$ is concave. So the higher the reference-point $M$, the more the investor behaves as a risk seeker and the less as a risk averse.

Now we are ready to provide a normative foundation to the disposition effect bias.

Let the investor reference-point $M$ be the purchase price of the stock under consideration (see Odean, 1998). By Definition 1.a, during a bull market trend it results $M<m$, so the purchase price $M$ is smaller than the market stock price $m$. Since the utility function is concave for market stock prices higher than the purchase price $M$, the investor is risk averse. That gives a sound explanation as to why investors in bull markets are inclined "to unload their winning positions too early" to prevent disagreeable losses. Conversely by Definition 1.b, during a bear market trend it results $M>m$, the purchase price $M$ is higher than the market stock price $m$. The utility function is convex over this market stock price interval and the investor becomes gain seeking. That explains why investors in bear markets do not want to suffer losses and so tend "to hold their losing positions too long".

\section{Conclusions}

Recent empirical studies have documented that investors are more likely to behave with loss aversion during bull markets rather than during bear ones (see Hwang and Satchell, 2010; Hofschire et al 2013). In this short note we theoretically formalize this behavioral pattern.

At first using the benchmark-based method we extrapolate the risk preferences through the personal expectations about the market trend. Then, we formalize the sentiment of loss aversion captured by the Kahneman and Tversky (1979, p. 279) dictum "losses loom larger than gains"; and the sentiment of gain appetite described through the quote "gains loom larger than losses" (see Sacchi and Stanca, 2014; Mellers and Ritov, 2010). Under mild technical assumptions, which are satisfied by the most popular utility functions we show that investors are normatively driven to be loss averse during bull markets and to be gain seeking during bear ones. 
Our findings also have practical implications. In fact they offer a sound explanation to the disposition effect, described by Shefrin and Statman (1985)'s words as that biased attitude that drives investors in bull markets to "sell winners too early" and in bear markets to "ride losers too long".

\section{Acknowledgments}

The Authors would like to thank Karim Abadir, Mario Ghossoub, Vasileios Kallinterakis, Stephen Satchell and Holger Stephan for their valuable comments and suggestions. The usual disclaimer applies.

\section{References}

Abadir, K. M. (2005). The Mean-Median-Mode Inequality: Counterexamples. Econometric Theory, 212 , 477-482. https://doi.org/10.1017/S0266466605050267

Abdellaoui, M., Bleichrodt, H., Paraschiv, C. 82007). Loss Aversion Under Prospect Theory: A Parameter-Free Measurement. Management Science, 53(10) 1659-1674. https://doi.org/10.1287/mnsc.1070.0711

Abdous, B., \& Theodorescu, R. (1998). Mean, median, mode IV. Statistica Neerlandica, 52, 356-359. https://doi.org/10.1111/1467-9574.00089.

Arnold, B. C., \& Groeneveld, R. A. (1995). Measuring Skewness with Respect to the Mode. The American Statistician, 49(1), 34-38. https://doi.org/10.2307/2684808

Barberis, N., \& Xiong, W. (2009). What Drives the Disposition Effect? An Analysis of a Long-standing Preference-based Explanation. Journal of Finance, 6451-784. https://doi.org/10.1111/j.1540-6261.2009.01448.x

Berhold, M. H. (1973). The use of distribution functions to represent utility functions. Management Science, 19 , 825-829. https://doi.org/10.1287/mnsc.19.7.825

Borch, K. (1968). Decision rules depending on the probability of ruin. Oxford Economic Papers, 20, 1-10. https://doi.org/10.1093/oxfordjournals.oep.a041075

Bordley R., LiCalzi, M., \& Tibiletti, L. (2017). A target-based foundation for the "hard-easy effect" bias. In Bilgin M., Danis H., Demir E., Can U. (Eds.), Country Experiences in Economic Development, Management and Entrepreneurship. Eurasian Studies in Business and Economics, 5. https://doi.org/10.1007/978-3-319-46319-3-41

Bordley, R. F., \& LiCalzi, M. (2000). Decision analysis using targets instead of utility functions. Decisions in Economics and Finance, 23, 53-74. https://doi.org/10.1007/s102030050

Bordley, R., Tibiletti, L., \& Uberti, M. (2016). Loss Aversion and Gain Appetite in the Small and in the Large. International Mathematical Forum, 11(14), 673-678. https://doi.org/10.12988/imf.2016.6558

Castagnoli, E., \& LiCalzi, M. (1996). Expected Utility without Utility. Theory and Decision, 413, $281-301$. https://doi.org/10.1007/BF00136129.

Charness G., Gneezy U., \& Imas A. (2013). Experimental methods: Eliciting risk preferences. Journal of Economic Behavior \& Organization, 87, 43-51. https://doi.org/10.1016/j.jebo.2012.12.023

Duxbury, D. (2015). Behavioral finance: insights from experiments I: theory and financial markets. Review of Behavioral Finance, 7(1), 78-96. https://doi.org/10.1108/RBF-03-2015-0011

Fabozzi, F. J. (2009). Institutional Investment Management: Equity and Bond Portfolio Strategies and Applications. Wiley, New Jersey.

Gnedin, A., \& Pitman, J. (2008). Moments of convex distribution functions and completely alternating sequences. Institute of Mathematical Statistics. Collections Probability and Statistics: Essays in Honor of David A. Freedman, 2, 30-41. https://doi.org/10.1214/193940307000000374

Groeneveld, R. A., \& Meeden, G. (1977). The Mode, Median, and Mean Inequality. The American Statistician, $31(3), 120-121$.

Heath, C., Larrick, R., \& Wu, G. (1999). Goals as Reference Points. Cognitive Psychology, 38, 79-109. https://doi.org/10.1006/cogp.1998.0708.

Hofschire, D., Embo-Mattingly, L., Gold, E., \& Blackwell, C. (2013). Is Loss aversion causing Investors to Shun Equities? Market Perspectives, Fidelity Investments, Leadership series, Market perspectives, February, 1-5.

Hwang, S., \& Satchell, S. E. (2010). How Loss Averse Are Investors in Financial Markets? Journal of Banking \& Finance, 34, 2425-2438. https://doi.org/10.1016/j.jbankfin.2010.03.018 
Jakóbczak, D. J. (2015). Analyzing Risk through Probabilistic Modeling in Operations Research, IGI Global.

Jannatunnesa. (2017). An Evaluation of the Factors Influencing Investors' Perception in Bangladesh Stock Market. International Journal of Business and Management, 12(5), 89-103. https://doi.org/10.5539/ijbm.v12n5p89

Kahneman, D., \& Tversky, A. (1979). Prospect Theory: An Analysis of Decisions Under Risk. Econometrica, 472, 263-91. https://doi.org/10.2307/1914185

Kaniel, R., Saar, G., \& Titman, S. (2008). Individual Investor Trading and Stock Returns, The Journal of Finance, 63(1), 273-310. https://doi.org/10.1111/j.1540-6261.2008.01316.x

LiCalzi, M., \& Sorato, A. (2006). The Pearson system of utility functions. European Journal of Operational Research, 172, 560-573. https://doi.org/10.1016/j.ejor.2004.10.012

MacGillivray, H. L. (1981). The Mean, Median, Mode Inequality and Skewness for a class of densities. Australian Journal of Statistics, 23(2), 247-250. https://doi.org/10.1111/j.1467-842X.1981.tb00784.x

Markowitz, H. (1952). The Utility of Wealth. The Journal of Political Economy, 60(2), 151-158. https://doi.org/10.1086/257177

Mellers, B. A., \& Ritov, I. (2010). How beliefs influence the relative magnitude of pleasure and pain. Journal of Behavioral Decision Making, 23, 369-382. https://doi.org/10.1002/bdm.662

Muradoglu, G., \& Harvey, N. (2012). Behavioural finance: the role of psychological factors in financial decisions. Review of Behavioural Finance, 4(2), 68-80. https://doi.org/10.1108/19405971211284862

Odean, T. (1998). Are Investors Reluctant to Realize Their Losses? Journal of Finance, 53(5), 1775-1798. https://doi.org/10.1111/0022-1082.00072

Pratt, J. W. (1964). Risk Aversion in the Small and in the Large. Econometrica, 32(1-2), 122-136. https://doi.org/10.2307/1913738

Sacchi, S., \& Stanca, L. (2014). Asymmetric Perception of Gains versus Non-losses and Losses versus Non-gains: The Causal Role of Regulatory Focus. Journal of Behavioral Decision Making, 27, 48-56. https://doi.org/10.1002/bdm.1786

Shefrin, H., \& Statman, M. (1985). The Disposition to Sell Winners Too Early and Ride Losers Too Long: Theory and Evidence. The Journal of Finance, 40(3), 777-790. https://doi.org/10.2307/2327802

Tibiletti, L. (2017). The utility functions that satisfy the van Zwet asymmetry conditions, manuscript

Tversky, A., \& Kahneman, D. (1992). Advances in Prospect Theory: Cumulative Representation of Uncertainty. Journal of Risk and Uncertainty, 5, 297-323. https://doi.org/10.1007/BF00122574

Zwet, W. R. V. (1979). Mean, median, mode II. Statistica Neerlandica, 33, 1-5. https://doi.org/10.1111/j.1467-9574.1979.tb00657.x

\section{Notes}

Note 1 . If $F$ it not strictly unimodal, then $M$ will be the midpoint of the modal set.

Note 2. For values greater than the mode $M$ the density function $f$ is decreasing. If the distribution is absolutely continuous, it follows that $F^{\prime}=f$ is decreasing, so $F$ is concave.

Note 3. Castagnoli and LiCalzi (1996) call $T$ a von Neumann-Morgenstern benchmark and its c.d.f. $F$ a von Neumann-Morgenstern distribution.

Note 4. The van Zwet (1979) asymmetry conditions detect the asymmetry of the distribution. Specifically, the former van Zwet (1979) condition is sufficient for right-skewness expressed by the van Zwet "mean-median-mode inequality" such that mean $>$ median $>$ mode; the latter van Zwet (1979) asymmetry condition is sufficient for left-skewness expressed by the van Zwet "mean-median-mode inequality" such that mode $>$ median $>$ mean.

Note 5. It is easy to prove that loss aversion (gain appetite) is a weaker condition than risk-aversion

(risk-seeking).
Note 6. If the van Zwet asymmetry condition $u(m+x)+u(m-x) \leq(\geq) 1$ holds, then $M<(>) m$, see van Zwet (1979, Theorem 1). 


\section{Appendix}

Proof of Proposition 1.

a) Let $M<m$. The investor perceives to be in a bull market trend. By assumption, $T$ satisfies the van Zwet (1979) asymmetry condition $u(m+x)+u(m-x) \leq 1$ or $u(m+x)+u(m-x) \geq 1$. Since the van Zwet mean-median-mode inequality (Note 1) $M<m$ holds, it follows that

$u(m+x)+u(m-x) \leq 1$, for all $x \geq 0$, where $m-x \in I$ and $m+x \in I$.

Since $u(m)=0.5$, it follows

$u(m+x)+u(m-x) \leq 2 u(m)$, for all $x \geq 0$, so

$u(m+x)-u(m) \leq u(m)-u(m-x)$ for all $x \geq 0$.

Then $u$ exhibits loss aversion with respect to the median $m$.

Groeneveld and Meeden (1977) (see also Arnold and Groeneveld, 1995 eq. (2.4)) prove that if $u(m+x)+u(m-x) \leq 1$ than also $u(M+x)-u(M) \leq u(M)-u(M-x)$ for any $x \geq 0$. Then $u$ exhibits loss aversion with respect to the mode $M$. The proofs of case b) follow the same hint of those of cases a).

\section{Copyrights}

Copyright for this article is retained by the author(s), with first publication rights granted to the journal.

This is an open-access article distributed under the terms and conditions of the Creative Commons Attribution license (http://creativecommons.org/licenses/by/4.0/). 